\title{
ANALIZA UTICAJA ZEMLJOTRESA NA KRUŽNU TUNELSKU CEV U PODUŽNOM PRAVCU
}

\author{
Dragan Lukić ${ }^{1}$ \\ Predrag Petronijević ${ }^{2}$ \\ Elefterija Zlatanović ${ }^{2}$
}

УДК: 624.19:624.042.7

DOI: 10.14415/konferencijaGFS 2015.049

Rezime: U radu je opisan 3D numerički model odgovora konstrukcije tunelske kružne cevi u okolnoj sredini (tlo/stena) za slučaj seizmičkog dejstva u pravcu podužne ose tunela. Model simulira interakciju konstrukcije $i$ stenske mase u seizmičkim uslovima. Analizom su obuhvaćeni nelinearni efekti sadejstva sistema tunelska konstrukcija stenska masa. Za ilustraciju seizmičkog ponašanja primenjenog modela, analizirana su dva slučaja uz variranje različitih seizmograma. Prvi slučaj prezentuje tunel kod koga je omogućeno nesmetano pomeranje tačaka portala u pravcu ose tunela. U drugom slučaju modelom je simuliran tunel velike dužine kod koga su tačke na portalima vezane elastičnim osloncima.

Ključne reči: numerički model, dinamički odgovor, tunelska konstrukcija, analiza $u$ podužnom pravcu

\section{UVOD}

Podzemne građevine kao što su železnički, drumski i hidrotehnički tuneli, podzemni rezervoari za goriva i sl., pored ostalog, potrebno je proračunati i na očekivana seizmička dejstva. Kako su podzemni objekti u potpunosti ukopani u tlo/stenu, u uslovima potresa, javlja se složeno interaktivno delovanje konstrukcije i okolne sredine. Zato je nužna primena numeričkih modela koji će obuhvatiti najvažnije nelinearne efekte ponašanja sistema stena-konstrukcija u seizmičkim uslovima. U ovom radu najpre je sažeto opisan jedan 3D numerički model simulacije dinamičke interakcije sistema stena-konstrukcija. Potom je, za ilustraciju primene modela, analizirano seizmičko ponašanje kružne cevi za četiri različita slučaja zemljotresa.

Odgovor podzemnih objekata na seizmičke uticaje se znatno razlikuje od ponašanja nadzemnih konstrukcija. Masa objekta je zanemarljivo mala u odnosu na masu okolnog

\footnotetext{
${ }^{1}$ Prof. dr Dragan Lukić, dipl.inž. građ., Univerzitet u Novom Sadu, Građevinski fakultet Subotica, Kozaračka 2a, Subotica, Srbija, tel: 024554 300, e - mail: drlukic.lukic@gmail.com

2 Ass. Predrag Petronijević, dipl. inž. građ., Univerzitet u Nišu, Građevinsko-arhitektonski fakultet Niš, Aleksandra Medvedeva 14, 18000 Niš, Srbija, tel: 018588 200, e-mail: petronijevicpetronijevic@gmail.com

2 Ass. Elefterija Zlatanović, dipl. inž. građ., Univerzitet u Nišu, Građevinsko-arhitektonski fakultet Niš, Aleksandra Medvedeva 14, 18000 Niš, Srbija, tel: 018588 200, e-mail: elefterija2006@,Yahoo.com
} 
International conference

Contemporary achievements in civil engineering 24. April 2015. Subotica, SERBIA

tla. Stoga se može reći da se odgovor podzemnih građevina na seizmičke uticaje bazira na odgovoru (deformaciji) okolnog tla usled dejstva zemljotresa, kao i na dinamičkoj interakciji konstrukcije i tla, a ne na dinamičkim svojstvima same konstrukcije, kao u slučaju nadzemnih građevina [1],[11],[12]. Interakcija tunelskog objekta i okolnog tla pri seizmičkom dejstvu se ostvaruje po celom spoljašnjem obodu tunelske cevi. Interakcija zavisi od svojstava okolne sredine (tlo/stena) i od načina izvođenja, tj. načina iskopa i tipa podgradne konstrukcije. Odgovor tla na seizmičku pobudu se ogleda u vibracijama, deformacijama i lomu tla. Lom tla je karakterističan za plitko položene tunele i tunelske portale. Lom tla se može manifestovati i kroz pojavu: likvefakcije, nestabilnosti kosina i pokretanje rasednih zona [11],[12]. Vibracije tla usled prolaska seizmičkog talasa su veoma složene. Tri osnovna tipa deformacija tunelskih cevi usled seizmičkog dejstva su: aksijalne deformacije, podužno savijanje i smicanje (distorzija) poprečnog preseka. Deformacijske modele podzemnih konstrukcija su postavili Owen i Scholl, 1981 [2] a kasnije razvijali Wang, Penzien i Hashash [3],[4]. Najjednostavniji vid deformacije tunelske cevi su aksijalne deformacije (slika 2). One se javljaju kada se komponente seizmičkih talasa prostiru paralelno sa osom tunela, indukujući na taj način dilatacije stenske mase, koje se preko konture iskopa prenose na tunelsku cev u vidu podužnih dilatacija pritiska i zatezanja. Predmet ovog rada je upravo slučaj prostiranja podužnih seizmičkih talasa i njihov uticaj na pojavu deformacija i presečnih sila u tunelskoj konstrukciji.

Za određivanje seizmički indukovanih naprezanja u tlu najčešće se koristi pojednostavljen postupak koji se bazira na teoriji propagacije ravanskih harmonijskih talasa u homogenoj, izotropnoj, elastičnoj sredini. Pretpostavka uvođenja prostiranja harmonijskih talasa u ravni podrazumeva da seizmički talasi imaju jednake amplitude $u$ svim presecima duž tunelske konstrukcije i razlikuju se jedino u vremenu njihovog pojavljivanja. Detaljno obrazloženje ovog postupka može se naći u radovima Newmarka [7] i Yeh-a [8]. Prema ovom postupku, maksimalna deformacija tla (PGS - Peak Ground Strain), koja može biti deformacija pritiska ili smicanja, određuje se kao količnik maksimalne brzine kretanja tla (PGV - Peak Ground Velocity) u pravcu propagacije talasa i brzine seizmičkog talasa.

$$
P G S=\frac{P G V}{V}
$$

Na sličan način se dobija zakrivljenje tla $\chi$, kao drugi izvod poprečnog pomeranja po udaljenju, i dato je izrazom:

$$
\chi=\frac{P G A}{V^{2}}
$$

gde je PGA maksimalno ubrzanje tla upravno na pravac propagacije talasa. Ove relacije daju validne rezultate isključivo ukoliko je pravac za koji se traže deformacije paralelan sa pravcem propagacije talasa. Analitičko određivanje deformacija tunelskih konstrukcija usled prostiranja $\mathrm{P}, \mathrm{S}$ i R-talasa u homogenom, izotropnom i elastičnom medijumu, uz zanemarivanje interakcije tunelske cevi i okolnog tla, koristeći Newmarkove relacije predložili su St John i Zarah [9] (Tabela 1). 


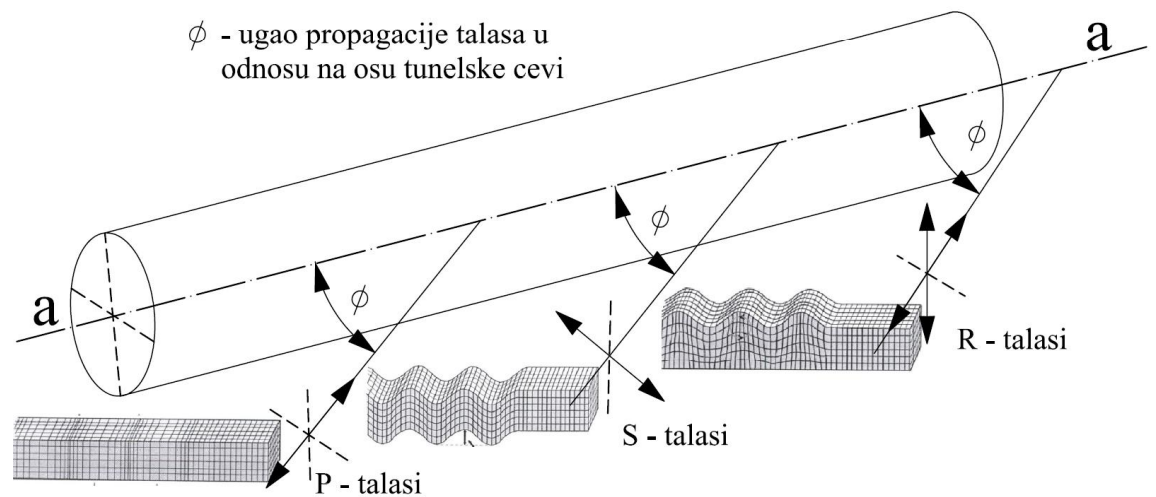

Slika 1. Uticaj ugla prostiranja seizmičkog talasa na aksijalno naprezanje i savijanje tunelske cevi [10]

Za P-talase (primarni, kompresioni ili longitudinalni talasi) i R-talase (Rayleigh-ev tip površinskih talasa, koji su karakteristični po niskim frekvencama, dugim periodama i velikim amplitudama u površinskom delu tla $i$ čiji je efekat najdestruktivniji) maksimalna deformacija se javlja za slučaj prostiranja talasa paralelno sa osom tunelske cevi. Kod S-talasa (sekundarni ili smičući talasi) maksimalni uticaj se ostvaruje za pravac prostiranja talasa po uglom od $45^{\circ}$ u odnosu na podužnu osu tunelske cevi (Tabela 2), što je detaljno prikazano u [6],[7],[8].

Tabela 1. Deformacije u tlu indukovane propagacijom seizmičkih talasa [9]

\begin{tabular}{|c|c|c|c|}
\hline Tip talasa & $\begin{array}{c}\text { Podužna } \\
\text { dilatacija }\end{array}$ & Poprečno smicanje & Zakrivljenje \\
\hline $\mathrm{P}$ - talasi & $\varepsilon=\frac{P G V_{P}}{V_{P}} \cos ^{2} \phi$ & $\gamma=\frac{P G V_{P}}{V_{P}} \sin \phi \cos \phi$ & $\chi=\frac{P G A_{P}}{V_{P}^{2}} \sin \phi \cos ^{2} \phi$ \\
\hline $\mathrm{S}$ - talasi & $\varepsilon=\frac{P G V_{S}}{V_{S}} \sin \phi \cos \phi$ & $\gamma=\frac{P G V_{S}}{V_{S}} \cos ^{2} \phi$ & $\chi=\frac{P G A_{S}}{V_{S}^{2}} \cos ^{3} \phi$ \\
\hline $\begin{array}{c}\mathrm{R} \text { - talasi } \\
\text { kompresiona } \\
\text { komponenta }\end{array}$ & $\varepsilon=\frac{P G V_{R}}{V_{R}} \cos ^{2} \phi$ & $\gamma=\frac{P G V_{R}}{V_{R}} \sin \phi \cos \phi$ & $\chi=\frac{P G A_{R}}{V_{R}^{2}} \sin \phi \cos ^{2} \phi$ \\
\hline
\end{tabular}

Pod pretpostavkom ponašanja tunelske kružne cevi kao idealno elastične grede [10], ukupna aksijalna dilatacija se može dobiti superponiranjem podužne dilatacije $\varepsilon$ i dilatacije usled savijanja:

$$
\varepsilon_{a}=\varepsilon+r \chi
$$

gde je $r$ rastojanje od neutralne ose do najudaljenije ivice poprečnog preseka tunelske cevi (poluprečnik za kružnu cev). Na osnovu jednačine 3, ukupna aksijalna deformacija u zavisnosti od vrste seizmičkog alasa može biti izražena relacijama:

$$
\varepsilon_{a}=\left[\frac{P G V_{P}}{V_{P}} \cos ^{2} \phi+r \frac{P G A_{P}}{V_{P}^{2}} \sin \phi \cos ^{2} \phi\right] \text { za P talase }
$$




$$
\begin{gathered}
\varepsilon_{a}=\left[\frac{P G V_{S}}{V_{S}} \sin \phi \cos \phi+r \frac{P G A_{S}}{V_{S}^{2}} \cos ^{3} \phi\right] \text { za S talase } \\
\varepsilon_{a}=\left[\frac{P G V_{R}}{V_{R}} \cos ^{2} \phi+r \frac{P G A_{R}}{V_{R}^{2}} \sin \phi \cos ^{2} \phi\right] \text { za R talase }
\end{gathered}
$$

\section{DEFINISANJE PROBLEMA I NUMERIČKI MODEL}

U radu je razmatran najjednostavniji vid deformacije tunela, tj. slučaj kada je oscilovanje čestica tla paralelno sa podužnom osom tunela. Ovakav vid seizmičkih talasa uslovljava dilataciju stenske mase koja se prenosi na konturu tunelske cevi u vidu podužnih dilatacija pritiska i zatezanja (slika 2).
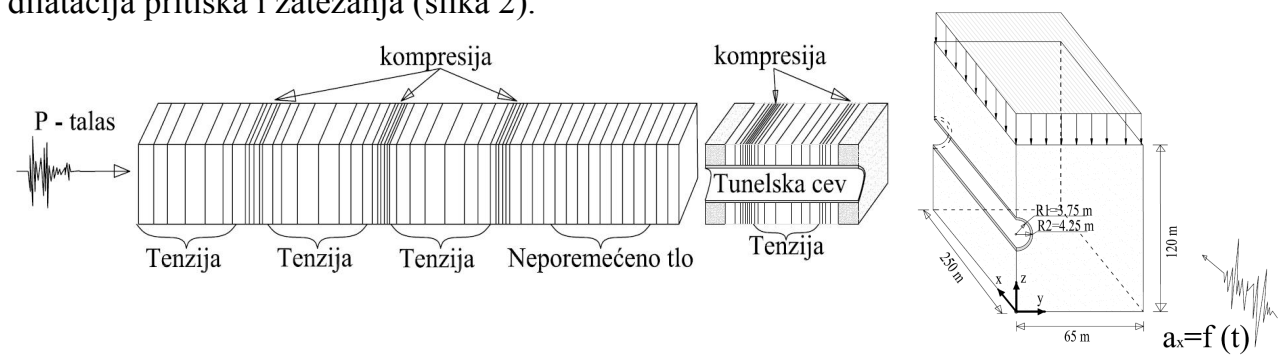

Slika 2. Aksijalne deformacije tunela usled dejstva zemljotresa [2], geometrija numeričkog modela

U zavisnosti od odnosa veličine talasne dužine seizmičkih talasa i dužine tunela moguća su dva slučaja. Ukoliko je dužina tunela veća od talasne dužine seizmičkih talasa, javlja se priraštaj ili opadanje napona u stenskoj masi koji su paralelni sa osom tunela. U suprotnom, podužni naponi su mogući samo do vrednosti kojima odgovara dilatacija jednaka razlici maksimalne i minimalne dilatacije koja se ostvaruje u tlu na delu talasne dužine [11]. U mekim terenima sa slabim karakteristikama dolazi do interakcije i pojave smičućih napona između konstrukcije i tla. Za dovoljno velike vrednosti smičućeg napona na kontaktu tlo-obloga dolazi do proklizavanja, a interakcije se svodi samo na udeo koji može da se prenese trenjem.

Numerički model korišćen za analizu seizmičkog odgovora je kružna tunelska cev u sloju lošeg-mekog tla (slika 3). Debljina nadsloja je $\mathrm{Hc}=50 \mathrm{~m}$, prečnik tunela $\mathrm{D}=8.0 \mathrm{~m}$, usvojena debljina tunelske obloge je $50 \mathrm{~cm}$ a dužina tunela je $250 \mathrm{~m}$. Moduo elastičnosti betona je usvojen $\mathrm{E}_{\mathrm{T}}=30 \mathrm{GPa}$, Poisson-ov koeficijent $\nu=0.25$ i gustina $\rho=25000 \mathrm{~kg} / \mathrm{m}^{3}$. Za opis ponašanja tla usvojen je moduo elastičnosti $E_{S}=50 \mathrm{MPa}$, Poisson-ov koeficijent $v=0.38$, gustina $\rho_{\mathrm{S}}=18000 \mathrm{~kg} / \mathrm{m}^{3}$ i prigušenje od $2 \%$ karakteristično za tla slabijih karakteristika. Simetrija je primenjena iz razloga racionalnog korišćenja računarskih resursa. Razmatrana je uzdužna polovina modela. U tačkama na osi simetrije postavljeni su transverzalni zglobovi, na bočnim stranama modela pokretni vertikalni oslonci, a na donjoj strani modela nepokretni oslonci. Za vezu tunelske cevi i stenske mase upotrebljeni su link (gap) elementi bez zazora i sa aksijalnom krutošću od 250000kN/m.

\section{6}


Међународна конференција

Савремена достигнућа у грађевинарству 24. април 2015. Суботица, СРБИЈА

Krutost u oba poprečna pravca je usvojena $20000 \mathrm{kN} / \mathrm{m}$. Razmatrana su dva slučaja. Prvi slučaj prezentuje tunel sa slobodnim portalima, kod koga je omogućeno nesmetano pomeranje tačaka na granici medijuma u pravcu ose tunela. U drugom slučaju je simuliran „dugačak“ tunel kod koga su čvorovi na portalnim stranama vezani elastičnim osloncima. Za modeliranje elastičnih oslonaca na krajnjim stranama modela upotrebljeni su u kombinaciji multilinear i damper link elementi. Oslanjanje je izvršeno u čvorovima primarne mreže konačnih elemenata (bez progušćenja prema tunelskoj cevi) sa krutošću $3200000 \mathrm{kN} / \mathrm{m}$, koeficijentom prigušenja od 0,8 i eksponentom prigušenja od 0.2 .

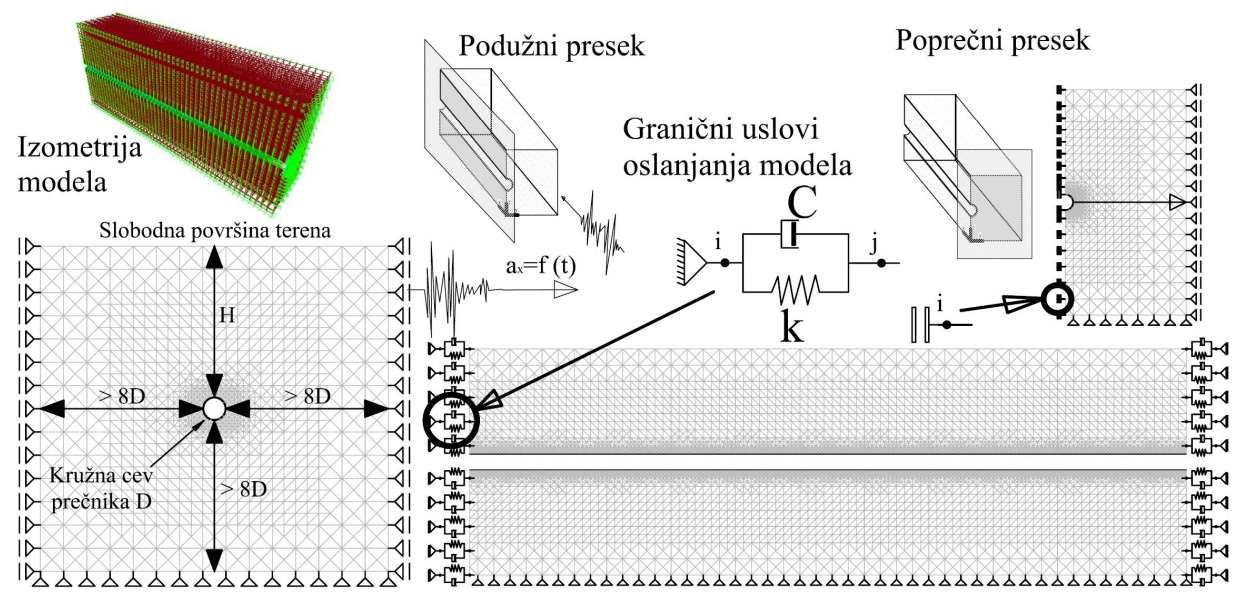

Slika 3. Dispozicija i granični uslovi numeričkog modela [2], geometrija modela

Mreža konačnih elemenata je generisana sa postepenim progušćenjem od kontura modela prema tunelskoj cevi. Usvojeno je 66 čvorova u jednom preseku na konturi tunelske cevi. Model je sadržao 1600 shell, 59200 solid i 3600 kontaktnih link elemenata.

\section{REZULTATI ANALIZE I DISKUSIJA}

Prvim korakom analize je simuliran proces izgradnje tunela. Izvršen je proračun primarnog naponskog stanja i deformacija koje su postojale u neporemećenom tlu pre izgradnje tunelske cevi. Primarno naponsko stanje zavisi isključivo od visine nadsloja i parametra elastičnosti medijuma, jer je stena u tom trenutku opterećena isključivo sopstvenom težinom i težinom nadsloja. Dobijeni rezultati prvog dela analize nisu predmet ovog rada i nisu prezentovani. U drugom koraku modelu je dodata tunelska cev, a izbačeno tlo unutar nje. Naponsko stanje na kraju drugog koraka predstavlja početno stanje napona za dinamičku analizu.

Treći korak proračuna je dinamička analiza (nonlinear modal time-history analysis) i izvršena je metodom integracije za dva zapisa realnih zemljotresa: zemljotres El Centro, Maj 18, 1940; zemljotres San Fernando, California, Februar 9, 1971. Na slici 4 su 
International conference

Contemporary achievements in civil engineering 24. April 2015. Subotica, SERBIA

prikazani akcelerogrami četiri zemljotresa upotrebljena u numeričkoj analizi. Svi akcelerogrami su skalirani na maksimalnu vrednost ubrzanja $\mathrm{a}_{\max }=0.4 \mathrm{~g}$.

Na slici 5 su prikazana pomeranja tačaka krune obloge tunelske cevi u pravcu podužne tunelske ose. Prikazana su uporedna pomeranja za oba razmatrana slučaja: slobodne i elastično oslonjene poprečne stranice modela. Odnos pomeranja za ova dva modela je od 4 do 10 puta u korist slobodno oslonjenog modela. Iako su svi primenjeni akcelerogrami skalirani na istu vrednost maksimalnog ubrzanja, evidentno je da se pomeranja značajno razlikuju. Odnos maksimalnog i minimalnog pomeranja za isti model i za sve razmatrane slučajeve akcelerogama je približno tri.
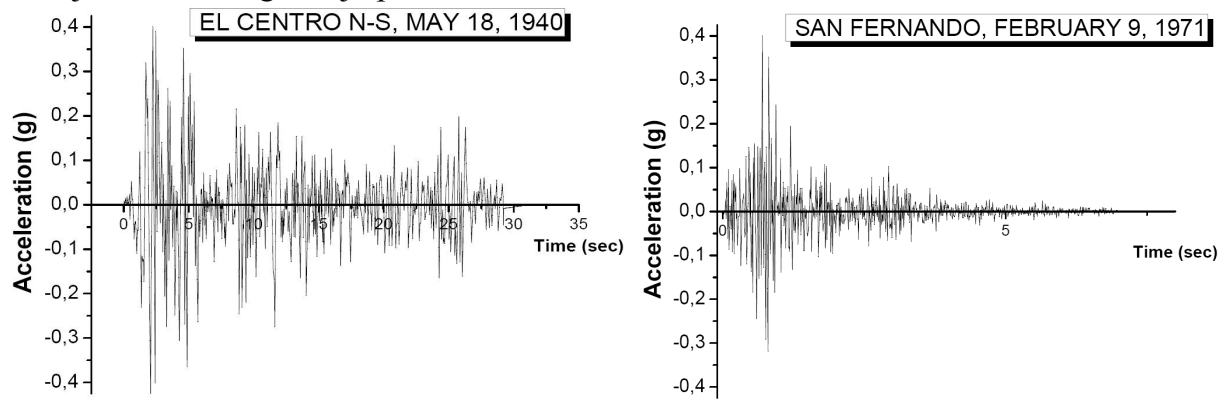

Slika 4. Akcelerogrami korišćeni u numeričkim analizama
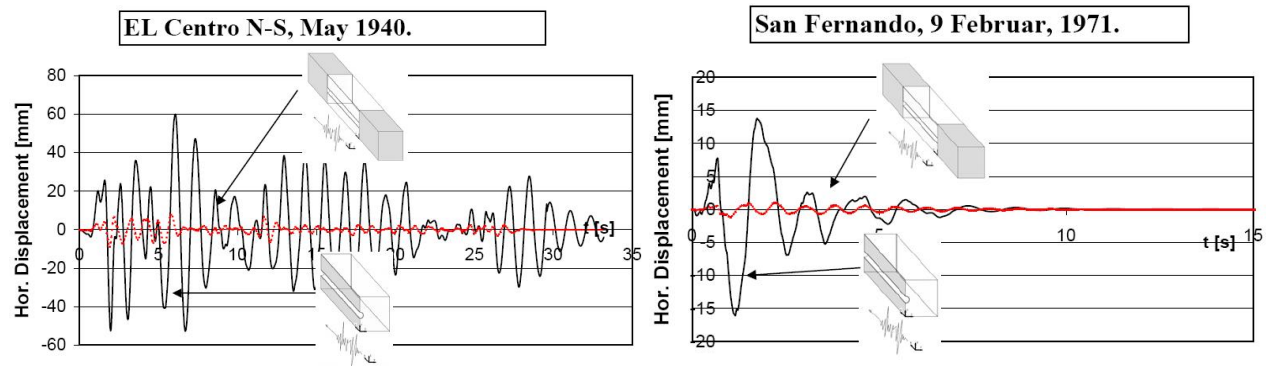

Slika 5. Aksijalna deformacija (pomeranje tunelske konstrukcije u pravcu ose tunela) usled dejstva zemljotresa

Na slici 6 su prikazane vrednosti ubrzanja tačaka krune obloge tunela. Za slučaj modela sa slobodnim poprečnim (portalnim) stranama vrednosti ubrzanja su veće. Veličina ubrzanja ne korespondira direktno sa pomeranjima dobijenim numeričkom analizom, tj. najmanja ubrzanja je dao El centro koji ujedno izaziva najveća pomeranja.
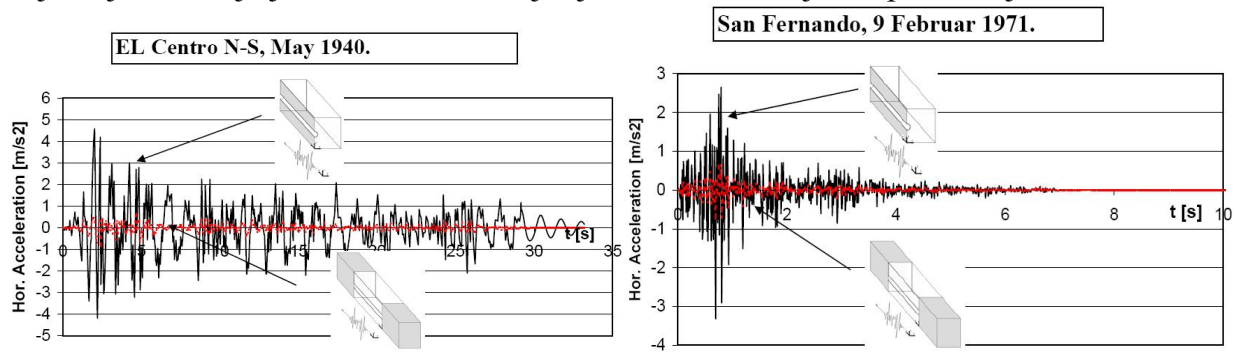

Slika 6. Dijagrami ubrzanja tačaka tunela usled dejstva zemljotresa 
Међународна конференција

Савремена достигнућа у грађевинарству 24. април 2015. Суботица, СРБИЈА

U projektovanju tunelskih konstrukcija sa aspekta seizmičkih uticaja, glavni problem je određivanje presečnih sila u tunelskoj oblozi, što omogućava bolje sagledavanje dinamičke interakcije tunelske obloge i okolnog tla. Na slici 7 je prikazana promena napona $\sigma_{11} \mathrm{u}$ kruni betonske tunelske konstrukcije. $U$ zavisnosti od frekventnih karakteristika primenjenog akcelerograma u znatnoj meri zavisi i funkcija promene naponskog stanja. Za zemljotres El Centro je nepovoljniji slučaj modela sa elastično oslonjenim čeonim ravnima. Maksimalni naponi u pravcu ose tunelske cevi koji se javljaju su $\min _{11}=-9,1 \mathrm{MPa} i \max _{11}=8,9 \mathrm{MPa}$. Za zemljotres San Fernando naponi su manji, ali je karakteristično da je nepovoljniji slučaj promene napona za model sa slobodnim portalnim ravnima.
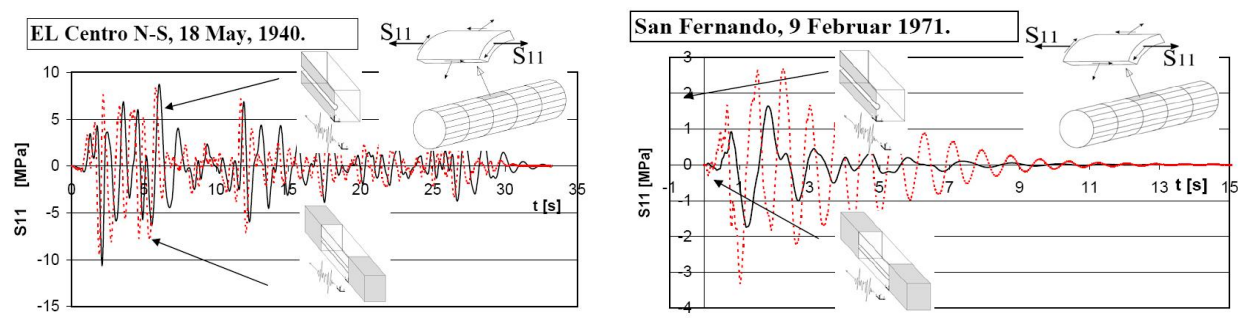

Slika 7. Promena napona S11 u oblozi tunelske cevi

\section{ZAKLJUČAK}

Analiza podzemnih objekata na seizmičke uticaje predstavlja kompleksan problem, koji obuhvata više naučnih disciplina uključujući dinamiku tla, stena i konstrukcija, zatim geologiju, seizmotektoniku i inženjersku seizmologiju. Odgovor tunelske cevi na seizmička dejstva prevenstveno zavisi od odgovora okolnog tla, a ne od inercije same tunelske konstrukcije. Tuneli se u znatnoj meri razlikuju od nadzemnih konstrukcija, pre svega zbog činjenice da su sa svih strana okruženi tlom (stenom), kao i u pogledu naglašenosti jedne dimenzije u odnosu na druge dve. Oštećenja tunela nastala za vreme zemljotresa uslovljavaju značajne ekonomske gubitke i posledice. Upravo iz tog razloga, tunelske konstrukcije u okviru saobraćajne infrastrukture zahtevaju nalaženje optimalnog rešenja za aseizmičko projektovanje i građenje.

Oštećenja tunelskih konstrukcija izazvana su u najvećoj meri maksimalnim ubrzanjima i brzinama kretanja tla uslovljenih zemljotresom. Preliminarni rezultati numeričke analize pokazuju da je mogućnost amplifikacije ubrzanja tačaka tunelske cevi značajna. Dugotrajna dejstva zemljotresa su veoma kritična, jer dovode do zamora materijala, velikih deformacija i loma. Stoga se od svih primenjenih akcelerograma El Centro može zasigurno smatrati najdestruktivnijim zemljotresom.

\section{LITERATURA}

[1] Atsushi, K., Hideito M., et al.: Fundamental examination on mechanism of seismic damage of mountain tunnel, WTC, Proceedings. "Safe Tunnelling For The City 
and For The Environment”, Budapest, 2009.

[2] Yubing, Y. et al.: Numerical simulation of dynamic response of operating metro tunnel induced by ground explosion, Journal of Rock Mechanics and Geotechnical Engineering, 2010., Vol. 4, No. 2, pp 373-384.

[3] Zlatanović, E.: Analiza na seizmička dejstva i kriterijumi aseizmičkog Projektovanja i građenja tunelskih konstrukcija, Izgradnja, 2009., Beograd, br. 3-4, str. 123-130

[4] Owen, G.N., Scholl, R.E.,: Earthquake engineering of large underground structures. Report no. FHWA_RD-80_195. Federal Highway Administration and National Science Foundation, 1981.

[5] Hashash, Y.M.A., Hook, J.J., Schmidt, B., Yao, J.I.: Seismic design and analysis of underground structures. Tunnelling and Underground Space Technology, 2001.,16, pp. 247-293.

[6] Newmark, N.M.: Problems in wave propagation in soil and rocks, Proceedings of the International Symposium on Wave Propagation and Dynamic Properties of Earth Materials, 1967.,University of New Mexico Press, 7-26.

[7] Yeh, G.C.K.: Seismic analysis of slender buried beams, Bulletin of Seismological Society of America, 1974., 64, N. 5, pp. 1551-1562.

[8] St John, C.M., Zarah, T.F.: Aseismic design of underground structures, Tunneling and Underground Space Tehnology, 1987., N.2, pp. 165-197.

[9] Power, M.S., Rosidi, D., Kaneshiro, J.: Vol. III Strawman: screening, evaluation, and retrofit design of tunnels. Report Draft. National Center for Earthquake Engineering Research, Buffalo, New York. 1996.

[10] Scandella, L.: Numerical evaluation of transient ground strains for the seismic response analysis of underground structures, Politecnico di Milano, Dipartimento di Ingegneria Strutturale, dottorato di riceca in Ingegneria Strutturale, Sismica e Geotecnica, 2007.

[11] Shahrour, I., Khoshnoudian, F., Sadek, M., Mroueh H.: Elastoplastic analysis of the seismic response of tunnels in soft soils I. Tunnelling and Underground Space Technology, 2010., N.25, pp. 478-482.

[12] Shahrour, I., Rezaie, F.: An elastoplastic constitutive relation for the soil- structure interface under cyclic loading. Comput. Geotech., 1997., 21 (1), 21-39. 
Међународна конференција

Савремена достигнућа у грађевинарству 24. април 2015. Суботица, СРБИЈА

\section{ANALYSIS OF EARTHQUAKE EFFECTS ON THE CIRCULAR TUNNEL TUBE IN LONGITUDINAL DIRECTION}

Summary: The paper describes a 3D numerical model of structural response of a circular tunnel tube in a medium (soil/rock) in case of a seismic action in the direction of the longitudinal axis of the tunnel. The model simulates interaction of the structure and rock mass in seismic conditions. The analysis includes nonlinear effects of interaction of the tunnel structure - rock mass system. For illustration of a seismic behavior of the applied model, two cases were analyzed, using variation of four different seismograms. The first case presents a tunnel where unrestrained displacement of portal points in the direction of the tunnel axis is facilitated. In the second case, the model simulates a very long tunnel whose portal points are joined with elastic supports.

Keywords: numerical model, dynamic response, tunnel structure, analysis in longitudinal direction

Napomena: "Ovaj rad finansiralo je Ministarstvo za nauku i tehnološki razvoj Republike Srbije, Nemanjina 22-26 (Projekti TR 36028 i TR 36043)" 